\title{
A NOVEL INVESTIGATION INTO THE APPLICATION OF NON- DESTRUCTIVE EVALUATION FOR VIBRATION ASSESSMENT AND ANALYSIS OF IN-SERVICE PIPES
}

S. Noroozi ${ }^{\text {b }}$ A.G.A. Rahman ${ }^{\mathrm{a}}$, E. H. Cheng ${ }^{\mathrm{c}}$, M. Dupac ${ }^{\mathrm{b} *}$, O. Z. Chao ${ }^{\mathrm{d}}$, K.S Yee ${ }^{\mathrm{d}}$, K.K. Kuan ${ }^{\mathrm{d}}$

${ }^{a}$ Mechanical Engineering Faculty, University Malaysia Pahang, 26600 Pekan, Malaysia

${ }^{b}$ Department of Design and Engineering, Faculty of Science and Technology, Bournemouth University, Talbot Campus, Fern Barrow, Poole, Dorset, BH12 5BB, UK

'Quadrant 2 Technologies Sdn. Bhd., Kuala Lumpur, Malaysia

${ }^{d}$ Department of Mechanical Engineering, University of Malaya, 50603 Kuala Lumpur, Malaysia

${ }^{*}$ Corresponding author: Mihai Dupac, Department of Design and Engineering Faculty of Science \& Technology, Bournemouth University, Poole, Dorset, BH12 5BB, UK, E-mail: mdupac@bournemouth.ac.uk 


\section{A novel investigation into the application of non-destructive evaluation for vibration assessment and analysis of in-service pipes}

Flow induced vibrations that are close to resonance frequencies are a major problem in all oil and gas processing industries, so all piping systems require regular condition monitoring and inspection to assess changes in their dynamic characteristics and structural integrity in order to prevent catastrophic failures. One of the main causes of pipe failure is weak support causing low frequency high amplitude flow-induced vibration. This causes wear and tear, especially near joints due to their dissimilar stiffness resulting in fatigue failure of joints caused by vibration-induced high cyclic stress. Other contributing factors in pipe failure are poor or inadequate design, poor workmanship during installation or maintenance and inadequate or weak and flexible support. These pipes are usually required to work non-stop for 24 hours a day 7 days a week for weeks, months or years at a time. Regular monitoring and in-service dynamic analysis should ensure continuous and safe operation. A novel method of non-destructive testing and evaluation of these pipes, while in service, is proposed in this paper. This technique will enable early detection and identification of the root causes of any impending failure due to excess vibration as a result of cyclic force induced by the flow. The method pinpoints the location of the impending failure prior to condition-based maintenance procedures. The technique relies on the combined application of Operating Deflection Shapes (ODS) analysis and computational mechanics utilizing Finite Element Analysis (FEA), i.e. linear elastic stress analysis. Any structural modification to the pipes and their supports can then be applied virtually and their effects on the system can be analysed. The effect on vibration levels is assessed and verified. The effect of any change in the forces corresponding to changes in the Differential Pressure (DP) at constant flow rate through the pipes can then be estimated. It was concluded that maintaining the differential pressure above some "critical" threshold ensures the pipe operates under the allowable dynamic stress for a theoretically "indefinite" life cycle.

Keywords: modal analysis; vibrations; ODS; pipe; stress; non-destructive testing 


\section{Introduction}

Detecting, monitoring and predicting vibration are important and cost-effective approaches to identifying structural problems such as general wear and tear, possible imbalance or incompatible stiffness of structural components. Vibration only monitoring can only pinpoint the root causes of failures which are usually triggered by poor design, poor assembly and workmanship, misalignment, imbalance and poor maintenance. Pipes are a particular type of structure and have their own specific set of design and monitoring challenges. Often the failure of piping systems in the oil and gas industries results from incompatible structural stiffness between adjacent pipes or support structures which are usually due to sub-optimal design. Factors include nonuniform mass distribution and incompatible stiffness, especially when fluid momentum becomes greater than the stiffness of the pipe and its supporting structure. This can result in large displacements that can also lead to fatigue-induced failure. In such cases, the overall dynamic response is no longer the expected one and the system behaves in a completely different and unpredictable manner.

One of the main causes of the unpredictable behaviour of pipes is vibrations induced by the interaction between the structure (pipe walls and pipe supports) and the fluid flowing through the pipe. Generally the fluid behaves as a turbulent flow and exerts random pressures on the wall of the pipe. Fluid-structure interaction, turbulent flow fluctuations and unsteady pressure can induce a random excitation of the pipe and support structure which often leads to high vibrations. The high levels of vibration caused by random excitation are not due to resonance, but the root cause is commonly a caused by incompatible stiffness between the piping systems and their supporting structures. Such systems with weak structural integrity experience low frequency large amplitude vibrations resulting in premature failure [1]. 
It has been shown that the fluid-structure interaction phenomenon induces a significant dynamic response in the structure which affects the fluid forces acting on the inside walls of the pipes [2]. There are many case studies related to fluid-induced vibration of pipelines and some are reported in [1,3,4]. A vibration analysis of a 3dimensional piping system composed of curved and straight sections was performed in [5] using the wave approach and the results were compared to those obtained using the Finite Element Method (FEM). Other causes of unpredictable behaviour are high fluid velocity which can cause buckling in pipes that are supported at both ends, or pipes that are supported at one end. A structured and systematic assessment approach to the vibration of pipes was considered in [6]. This study also supported the initial observations that some of the main problems in the existing piping systems are due to poor or inadequate support systems. The general stability problem of vibrating pipes transferring fluid has been studied extensively in $[1,2]$. The nonlinear dynamics nature of a pipe conveying pulsating fluid was studied in [7] while the nonlinear dynamics of a curved pipe conveying fluid subject to harmonic excitation was studied in [8]. The phase shift effects of resonating pipes are discussed in $[9,10]$ and the dynamic structural response of bolted flange piping systems was studied in [11]. Perturbation analysis was used to provide a direct insight into how the parameters such as nonuniform mass, stiffness, non-proportional damping, or weak imperfections, can affect the phase shift. The post buckling effect in vibrating pipes which permit axial sliding, but not transverse deflection, was presented in [12].

In determining the dynamic behaviour of static structures in terms of their dynamic characteristics, e.g. natural frequency, damping and corresponding mode shape, experimental modal analysis (EMA) is a classical. For example, [13] conducted EMA to extract the dynamic characteristic of a 12-stage vertical pump. It must be 
however, be noted that classical EMA must always be performed on static structure or when the machine that is in 'shutdown' condition. This is because unaccounted force during operation can introduce misleading or erroneous results. Although extracting modal parameters while the system is in operation or in-service is not currently possible with EMA techniques but it is highly desirable, especially for a large and complex piping system that are required to be in service $24 / 7$ and stopping them can mean financial disaster in terms of loss revenue.

Another method of checking structures for signs of excess movement is commonly known as operating deflection shape (ODS) analysis. This experimental technique is a non-invasive and non-destructive approach used to monitor the overall dynamics and the condition of a system while in operation [14-18]. It is useful when classical condition monitoring is not possible or when a full 3D visualization of the dynamics of the motion is desirable. ODS analysis have been used [13] to determine the vibration or deflection pattern of a pump operating at a specific frequency. However, the traditional ODS analysis used in [13] was insufficient to measure the dynamic characteristics of the system, because general rotating machines produce sinusoidal excitation (a single frequency). Therefore two different techniques (EMA and ODS) must both be deployed separately, limiting their usage in certain applications.

In fact, random excitation by fluid flow in pipe creates a broadband excitation signature [19]. The broadband excitation by the flow will induce or excite all natural frequencies of the system within its frequency content/ bandwidth, hence the resulting vibration response will behave contribution from all of these excitations which are linearly proportional to the dynamic characteristics of the system. In other words, overlaid peak responses identified by ODS analysis indicate natural frequency region, while vibration pattern in this peak frequency can be recognized as mode shape (i.e. 
deflection shape of a structure when resonance occurs). This paper investigates the possibility of utilizing the broadband excitation characteristic of fluid flow to extract the dynamic characteristics of the piping system. In this way, the traditional ODS analysis can extend its capability to extract dynamic characteristics of an operating piping system, without the usage of EMA. So, performing ODS analysis in this case could behave like the common output-only modal analysis, i.e. operational modal analysis (OMA) which helps to reveal the natural modes of vibration in pipes. Figure 1 show the flow chart of the ODS analysis. The proposed method gives high competitive advantage due to its time and cost effective approach.

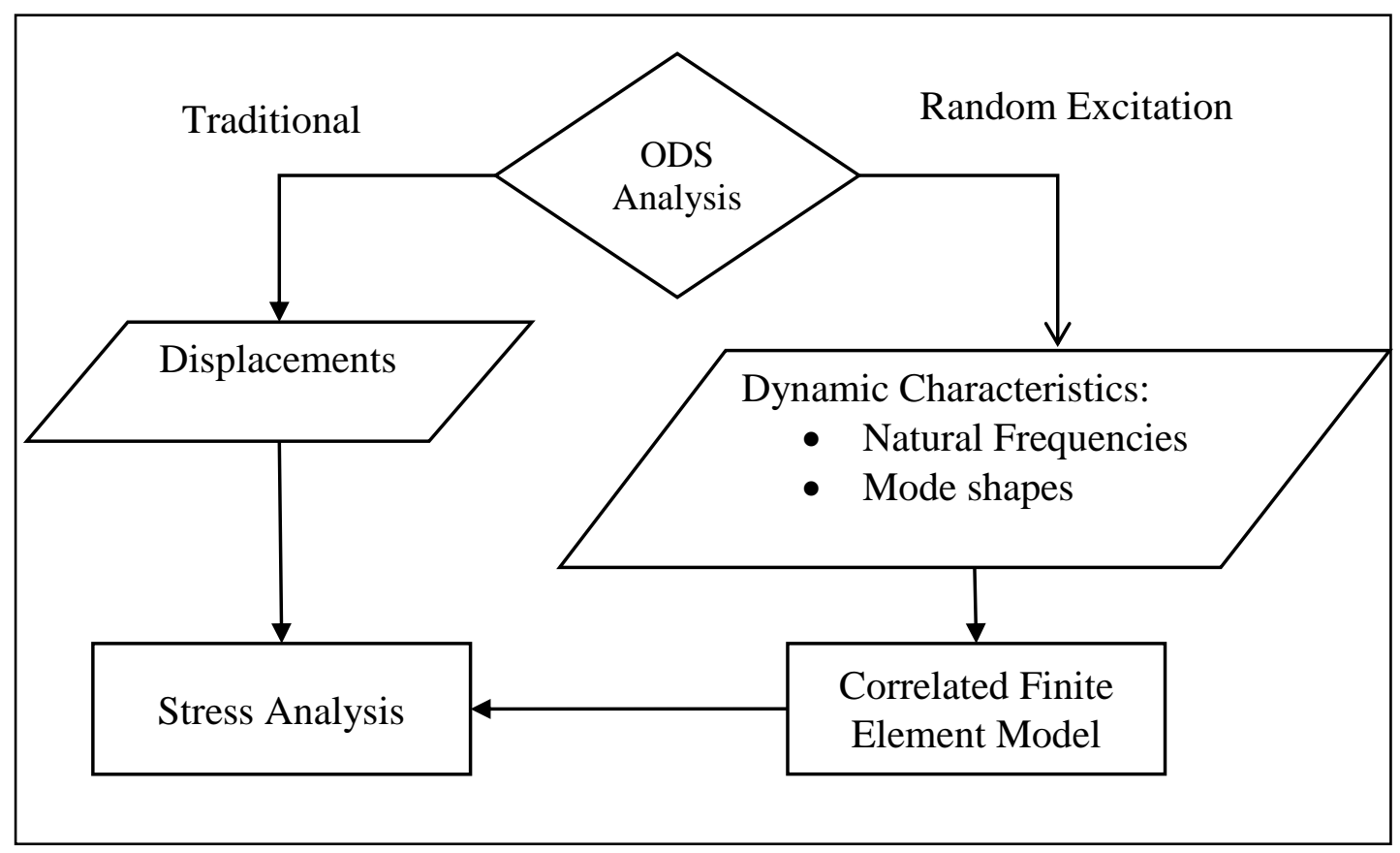

Figure 1. Flow chart of ODS Analysis

As introduced in [13], correlation between finite element (FE) model with EMA \& ODS results is a crucial step in a dynamic design verification (DDV) process for structural weakness identification purposes. Good correlation between them ensures reliable and valid analysis when using FE tool, such as virtual design modification [13], and dynamic stress analysis. In this study, we will focus on the later part. With the knowledge of modal parameters of the piping system obtained from the extended ODS 
approach, the measurement can be used further for correlation purpose. Once a good FEA model is achieved, further computational analysis, i.e., linear elastic stress analysis could be performed. This analysis is particularly important to evaluate the structural integrity and reliability of an operating fluid-structure system.

In this paper the outcome of the application of a novel non-destructive evaluation method for the vibration assessment and analysis of in-service pipes is presented. This investigation is based on the combined application of experimental technique, i.e. Operating Deflection Shapes (ODS) analysis and computational mechanics utilizing Finite Element Analysis (FEA), i.e. linear elastic stress analysis to assess the condition of an in-service pipe structure on oil pumping station that was showing signs of excess movement due to excess vibration. The root cause of these excess vibrations, as discussed above, were due to differential or fluctuating flow conditions resulting in non-steady state dynamics response, due to turbulence and fluctuating pressure or unsteady flow rate. The analysis also reveals that the differential pressure inside the pipe structure should be monitored and maintained above a certain threshold, as stated by the suppliers or standards, to ensure that the pipe operates under the allowable dynamic stress for a "theoretically infinite" life cycle.

\section{Problem Formulation}

\subsection{Modal Analysis and Operating Deflection Shapes (ODS) analysis}

\section{Modal Analysis -}

Modal analysis is used for investigating the dynamic behaviour of any system. This study enables an enhanced our understanding and identification of the root cause of vibration phenomena encountered in engineering by describing a system with its modal parameters namely the natural frequencies, natural damping and natural modes [20]. These three parameters comprehensively define the dynamic characteristics of a system. 
Currently, the three techniques used to extract these parameters are the classical Experimental Modal Analysis (EMA), the Operational Modal Analysis (OMA) [21-23] and Impact-Synchronous Modal Analysis (ISMA) [24, 25]. Conventional EMA requires the system to be in a complete shutdown state; which means no unaccounted excitation force induced into the system. In industrial applications, especially in petrochemical plants, the downtime cost is crucial. Thus, it is not practical to shut down the machinery to perform EMA. In practical situations where the system cannot be shutdown completely, OMA is sought. The challenges encountered in the OMA are that outputonly data can only be used for parameter identification and the noise-to-signal ratio in the measured data is much higher than in the controlled experiment in laboratory environment. Lack of knowledge of the input forces does affect the parameters extracted. Mode shapes obtained from OMA cannot be normalised accurately, subsequently affecting the development of mathematical models thereafter. ImpactSynchronous Modal Analysis (ISMA) that utilizes Impact-Synchronous Time Averaging (ISTA) and focuses on digital signal processing at the upstream of the collected data rather than the modal identification algorithm. It is effective in filtering out the non-synchronous cyclic load component, its harmonics and noises. ISMA has the advantages of the OMA and EMA combined. It carries out the analysis while the system is in operation and at the same time is able to provide the actual input forces in the transfer functions, hence, allowing for better modal extractions and mathematical model development.

The relationships between the structure's modal parameters and the system's frequency response function shall be established before the discussion on the experimental technique of modal analysis $[19,20,26]$. The modal parameters are extracted using Frequency Response Function (FRF) measurement techniques, 
Accelerometers are commonly used for Modal Analysis. Accelerometers measures acceleration and the transfer function relating force and acceleration in frequency, $\omega$ is termed as Accelerance, $\mathrm{A}$, and stated as

$$
A_{i j}(\omega)=\sum_{r=1}^{n} \frac{-\omega^{2} \phi_{i r} \phi_{j r}}{-\omega^{2}+2 \sigma_{r} \omega i+\omega_{o r}^{2}}
$$

where subscripts $i$ refer to the response point, $j$ to the forcing point and $r$ to the mode shape. The inputs (excitations) and the outputs (responses) of the system are now related by only the system modal parameters, namely the natural frequency $\omega_{\text {or }}$, mode shape $\phi_{r}$ and damping, $\sigma_{r}$.

In digital signal analysis, the auto and cross correlation are normally performed in the frequency domain in terms of auto and cross spectrum. The Fourier transforms of input $F_{q}(\omega)$, output $F_{x}(\omega)$ and their conjugates $\left(^{*}\right)$ are multiplied to estimate the transfer functions. The transfer function can be derived by dividing the Cross Power Spectrum $S_{x q}(\omega)$ of the input and output by the Auto Power Spectrum of the input $S_{q q}(\omega)$

$$
A_{1}(\omega)=\frac{F_{x}(\omega)}{F_{q}(\omega)} \cdot \frac{F_{q}^{*}(\omega)}{F_{q}^{*}(\omega)}=\frac{S_{x q}(\omega)}{S_{q q}(\omega)}
$$

\section{Operating Deflection Shapes (ODS) analysis -}

An Operating Deflection Shape (ODS) can measure the relative motion of in-service structures. It is recommended to perform ODS measurements, which can be planar, orbital or 3D, simultaneously and under constant operating conditions. Moreover, the measurement should show a signal having a high signal to noise ratio, so the measurement equipment does not affect the answer of the system and lesser averaging is 
later required. However, the "simultaneous" condition depends on the number of data acquisition channels and DOFs to be measured, while the "constant operating" condition depends on the system complexity and whether all DOFs are measured simultaneous or not.

There are three types of ODS, which are Time ODS, Spectral ODS and Runup/down ODS. While the time ODS measures the vibration of a structure as a function of time, the Spectral and Run-up/down ODS measures the vibration pattern at a discrete operating frequencies (typically done for rotating equipment). Since in a pipe operating structure no rotating equipment is employed, the time ODS is the method to be used. The measured time signal can be processed to show the pipe behavior over time. In this case study, the Spectral ODS is used instead because it is expensive to use time ODS where it needs a lot of data acquisition \& sensors to acquire the signals simultaneously.

From [26], if a system has vibrational modes, the dynamic response at time $t$ due to applied action at time $t^{\prime}$ is contributed by the superimposition of vibrational mode $r$ and is obtained by

$$
x(t)=\sum_{r=1}^{n} \frac{\phi_{r} \phi_{r}}{\omega_{d r}} \int_{0}^{t} Q\left(t^{\prime}\right) e^{-\sigma_{r}\left(t-t^{\prime}\right)} \sin \omega_{d r}\left(t-t^{\prime}\right) d t^{\prime}
$$

where $Q\left(t^{\prime}\right)$ is time-varying applied actions $\omega_{d r}$ is the eigenvalue of mode $\mathrm{r}, \sigma_{r}$ is the decay rate, and $\phi_{r}$ is the normalized mode shape or the eigenvector of the mode $r$.

In digital signal processing, the cross-power spectrum between each roving point DOF and the reference point DOF are used to determine the absolute amplitude if all measurement points. The cross-power spectrum can be written as

$$
S_{i j}(\omega)=F_{i}(\omega) \cdot F_{j}^{*}(\omega)
$$

where ${ }^{*}$ is the complex conjugate, $\mathrm{i}$ is the measured response and $\mathrm{j}$ is the reference response. Only the phase difference between the reference point and roving point is important. 
Meanwhile, the auto-power spectrum of the measured response can be written as

$$
S_{i i}(\omega)=F_{i}(\omega) \cdot F_{i}^{*}(\omega)
$$

where the variation in amplitude part of the auto-power spectrum output is used to measure the absolute amplitude of all points. Combining both the phase differences and amplitudes for all points when linked to the geometry will give the operating deflection shape.

\subsection{Measurement procedure description}

The need for a non-invasive testing and evaluation approach was justified by the "need to know" whether or not any high vibration based primarily on the vibratory stresses introduced into the piping by its running conditions, i.e., the fluid pipe interaction, may affect the overall structural integrity of the piping system and result in a catastrophic failure. Many times the apparently high vibration in pipes may not cause excessive stresses in the piping, but could cause excessive stresses to piping system that are attached to the vibrating pipe.

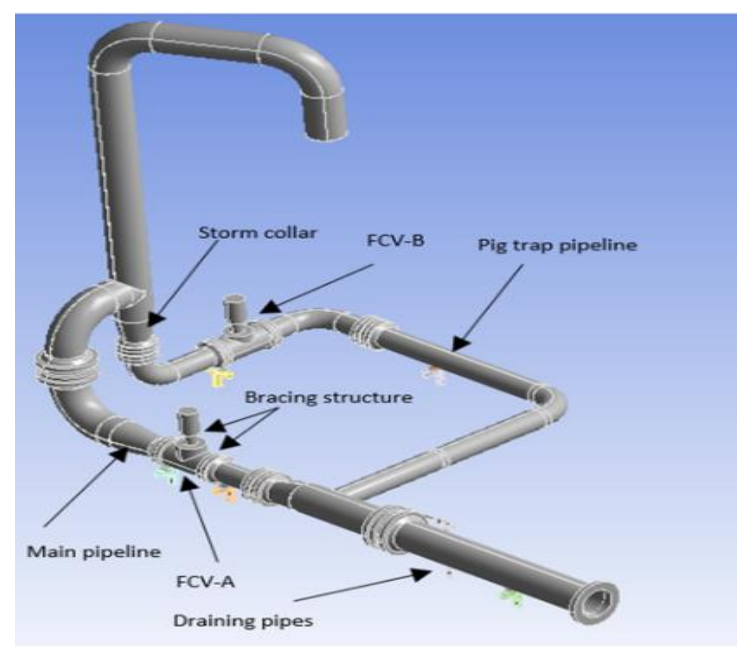

(a)

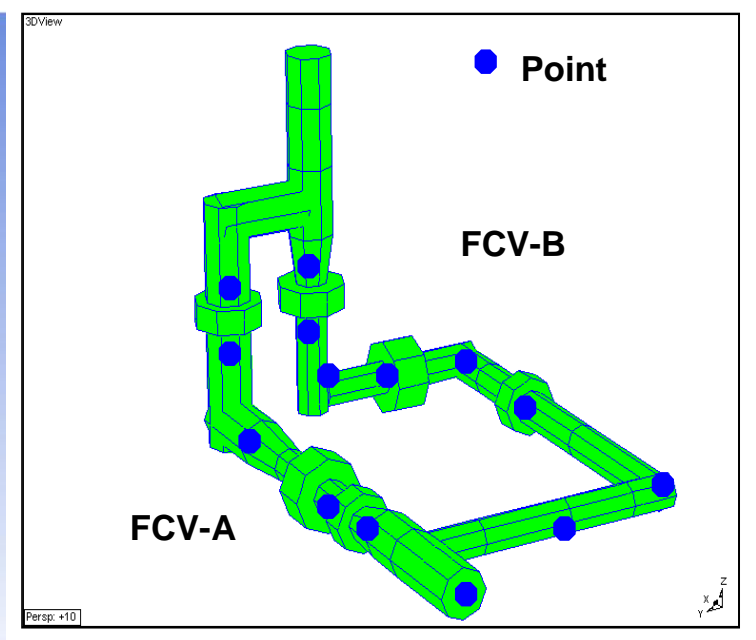

(b)

Figure 2. DSS Pipe (a) Main Pipe, and (b) Measurement Locations 
To assess the problem, measurements have been performed using the following items: 4 channel real-time data acquisition (DAQ) system, tri-axial and uni-axial accelerometers and related equipment; cables, magnetic base, DASYLab software and ME'scope software. The uni-axial accelerometer is used as reference at a fixed point while the tri-axial accelerometer is mounted from point to point on the piping structure (Figure 2(a)), in order to capture the 3D vibration signal (i.e. vibration in 3 principal directions, namely $\mathrm{X}, \mathrm{Y}, \mathrm{Z}$ ) at the predefined discrete set of geometrical positions. The measurement locations are illustrated as shown in Figure 2(b). All the measured vibration signals will be captured through a 4-channel DAQ module and hence it will be recorded in laptop using the virtual instrument (i.e. DASYLab software). The virtual instrument will proceed to calculate the vibration magnitude and phase difference between roving point to the reference point by using auto-power (Eq. (5)) and crosspower (Eq. (4)) spectrums respectively. Hence, the vibration distribution or pattern of the piping system can be computed and animated in ME'scope software for further analysis.

Several sets of vibration measurements were performed on piping systems and their support structures under different operation conditions. For a flow rate of 400mmscfd the next process conditions have been considered: Flow Control Valve (FCV)A and B opened @ 28\%,24\%,21\%,19\%,21\%,16\% and 19\% for a Differential Pressure (DP) of $100 \mathrm{kPa}, 200 \mathrm{kPa}, 500 \mathrm{kPa}, 650 \mathrm{kPa}, 700 \mathrm{kPa}, 850 \mathrm{kPa}$ and $950 \mathrm{kPa}$ respectively. The operating pressure of the piping system is $5000 \mathrm{kPa}$, with the fluid velocity of $11.38 \mathrm{~m} / \mathrm{s}$ in 24 inch diameter of piping, Reynolds number is $3.97 \times 10^{7}$, hence the flow are fully turbulence. The analysis covered the main Duplex Stainless Steel (DSS) piping system and also the pipe structure and fittings along the main pipe. This includes the main deck structure and bracing structure, as well as a $24 "$ pig trap 
piping and the storm collar ventilation and draining pipes. The piping systems at the flow control valves, upstream and downstream of the flow control valve A and B have also been considered. Most of the measurement locations are linked to obtain a wire mesh model in software to represent the overview of DSS pipe as show in Figure 2. All the collected data can be put into this model and visualize the vibration movement in the animation.

\section{Results}

An analysis was performed on the modal parameters measured using the MDT-Q2 data acquisition system. Initial processing of the signals by the use of virtual instruments generates the needed frequency response functions for various piping operating conditions. Post processing of the signals extracts the modal parameters to show mode shapes, natural frequencies and damping and to compare the relative displacement of the pipe system and to evaluate its dynamic response. All the measured answers in X, Y and Z-directions (according to different operating conditions and locations) are plotted into the allowable Piping Vibration Level versus Frequency for comparison as shown in Figure 3.

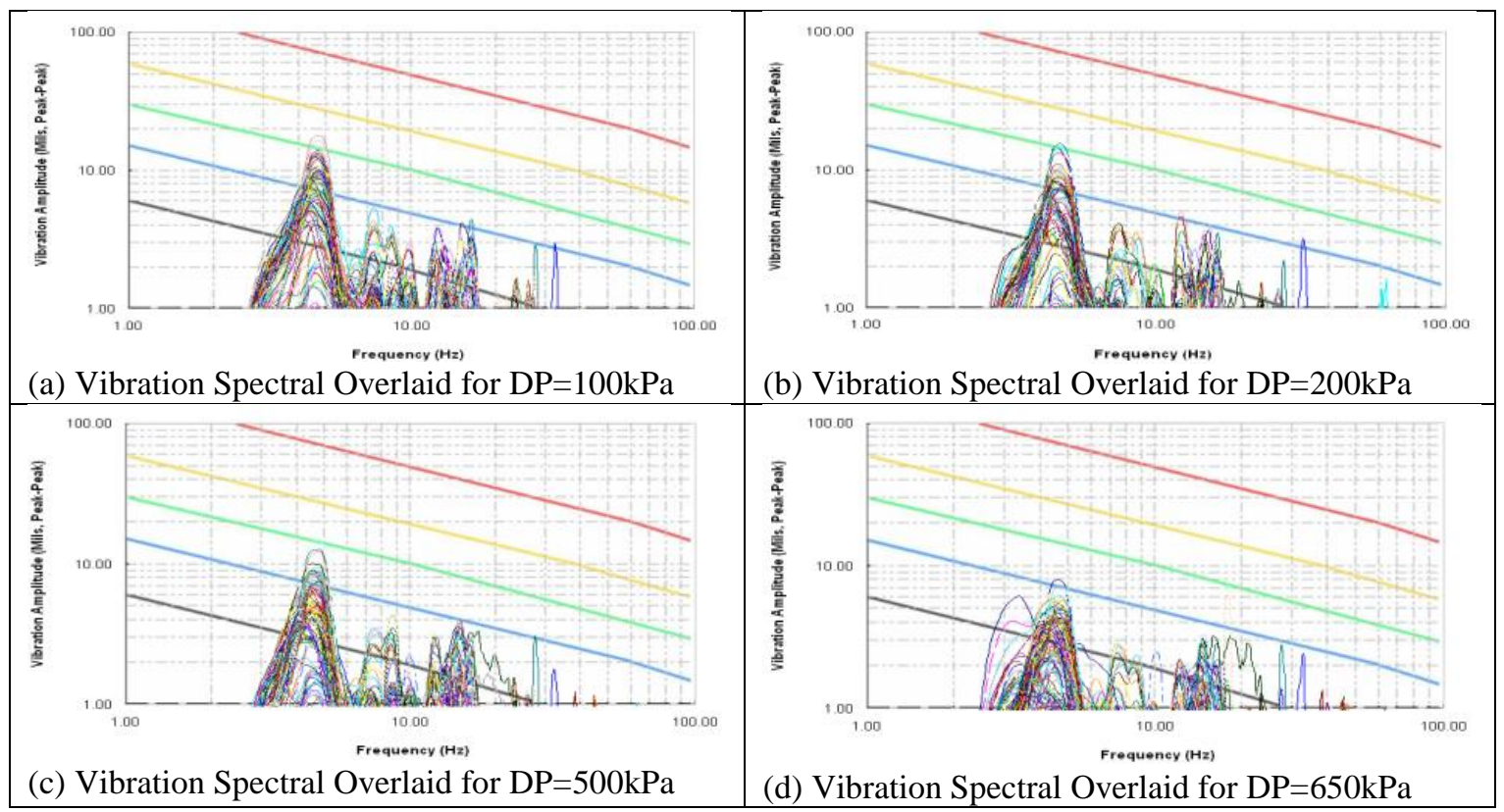



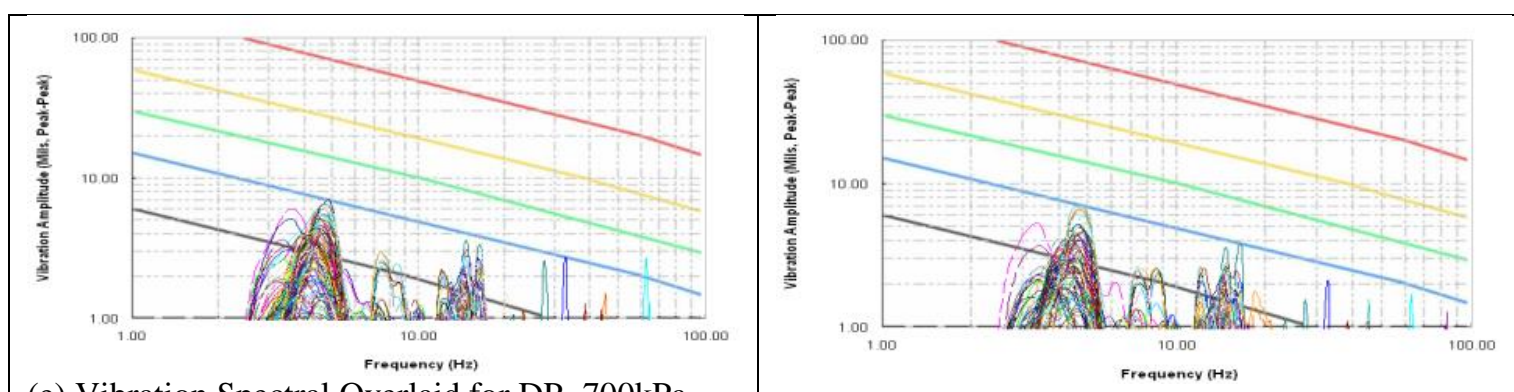

(e) Vibration Spectral Overlaid for $\mathrm{DP}=700 \mathrm{kPa}$

(f) Vibration Spectral Overlaid for $\mathrm{DP}=850 \mathrm{kPa}$

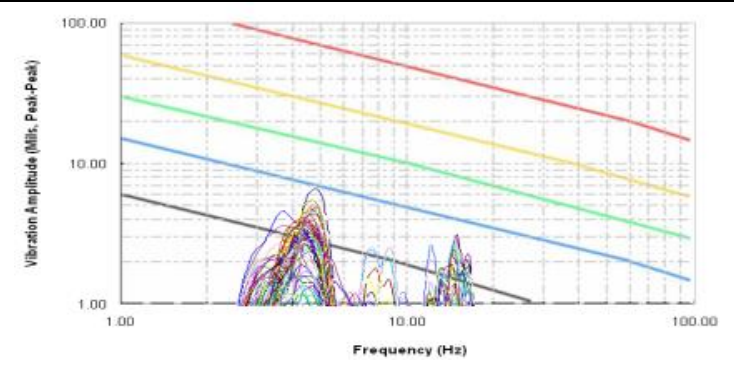

(g) Vibration Spectral Overlaid for $\mathrm{DP}=950 \mathrm{kPa}$

Figure 3. Vibration Spectral Overlaid for a Flow Rate of 400mmscfd at Various DP

The evaluation of whether or not the high vibrations represent a problem has to be based primarily on the vibratory stresses introduced into the piping. High vibration may not cause excessive stresses in the piping. However it could cause excessive stresses to the fittings along the high vibration main piping system.

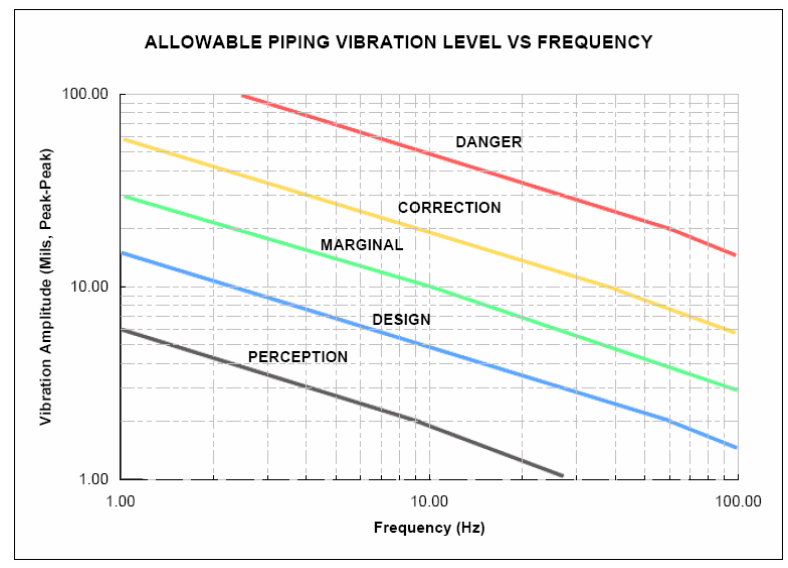

Figure 4. Allowable Piping Vibration Level versus Frequency [27]

Referring to Figure 4, whenever piping vibration amplitudes at the measured frequencies are greater than the danger line, piping failures are typical occurrences. When vibration levels are below the design line, very few failure cases have occurred. 
Therefore, the vibration versus frequency criteria can serve as a good starting point in evaluating piping vibrations to screen those systems that need further analysis.

ODS analysis is performed on DSS pipe. Figure 5(a) shows the overlaid ODS spectrums for DSS pipe which plot into the Allowable Piping Vibration Level versus Frequency for comparison. It is observed that the movement was dominated by two frequencies at $3.60 \mathrm{~Hz}$ and $4.56 \mathrm{~Hz}$. Figure 5(b) and Figure 5(c) show the movement of the DSS pipe at $3.60 \mathrm{~Hz}$ and $4.56 \mathrm{~Hz}$. It is observed that the movements are dominant in Y-direction at $3.60 \mathrm{~Hz}$ and dominant in $\mathrm{X}$ direction at $4.56 \mathrm{~Hz}$. The flow generates random excitation to the pipe. The output-only data due to random excitation are utilized to reveal the natural modes. Thus, the first 2 vibration modes are obtained at $3.60 \mathrm{~Hz}$ and $4.56 \mathrm{~Hz}$. A good and reliable FE model of DSS pipe is built based on correlation results between FEA and ODS. Once a good model is achieved, further analyses such as dynamics stress analysis can be performed computationally.

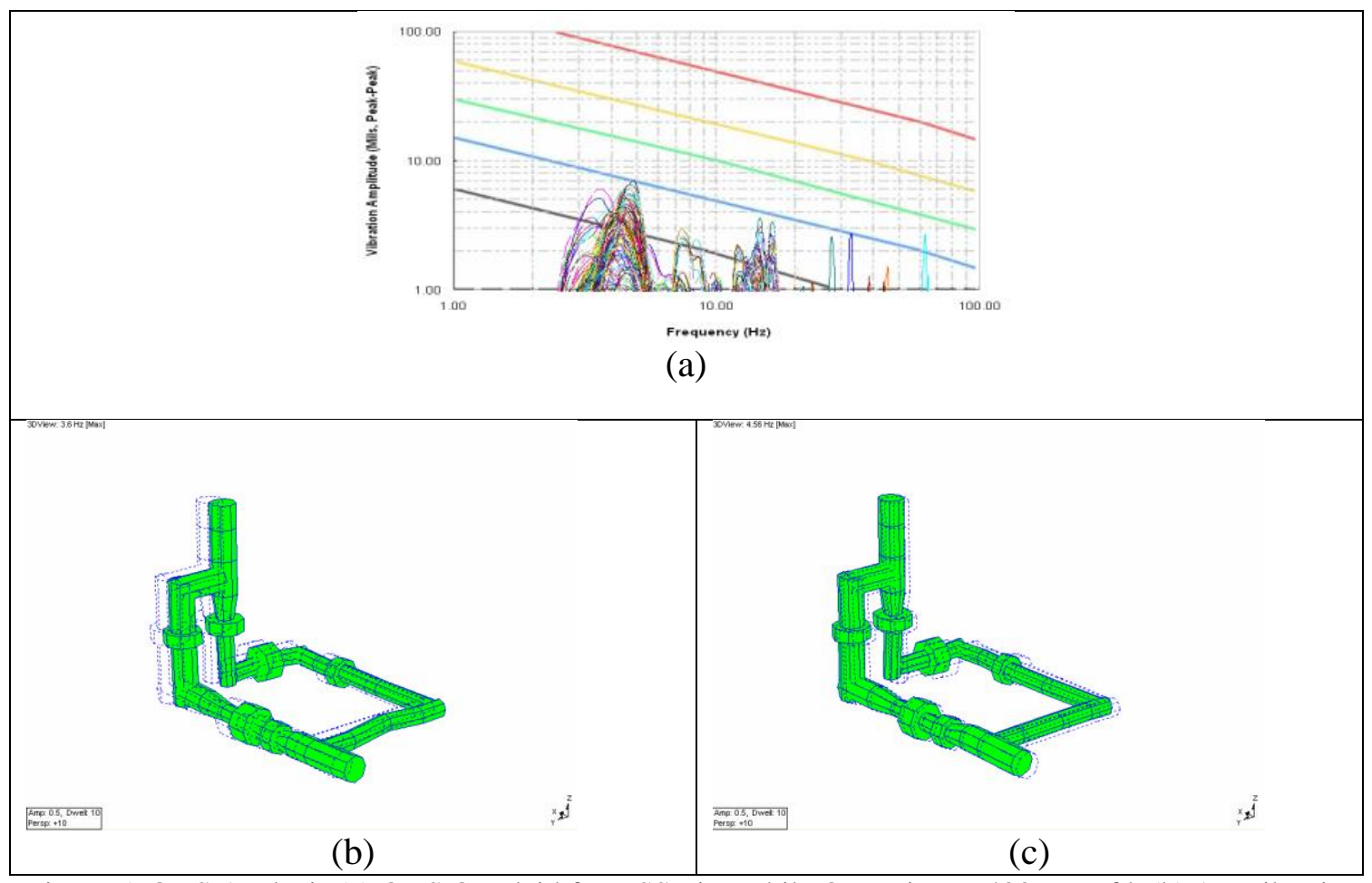

Figure 5. ODS Analysis (a) ODS Overlaid for DSS Pipe while Operating at 400mmscfd, (b) 1st Vibration Mode at $3.60 \mathrm{~Hz}$ (d) 2nd Vibration Mode at $4.56 \mathrm{~Hz}$ 
During the operating condition, the forces generated inside the pipe, are transmitted to the walls resulting on both stresses and vibrations. Dynamic Stresses, shown in Table 1 are calculated using a Finite Element Analysis (FEA) created in the ANSYS program, based on the displacement inputs obtained from site measurement. The correlation between FEA and ODS represents an important part of the verification process, as it allows detailed analysis of any design change to be carried out. We can also check their effect on the dynamic response, both for operating and non-operating conditions.

Table 1. Dynamics Stresses calculated using FEA based on the displacement inputs obtained from site measurement

\begin{tabular}{|c|c|c|}
\hline \multicolumn{2}{|c|}{ Stress Level } & \multirow{2}{*}{$\begin{array}{c}\text { Total Stress } \\
(\mathrm{M} 1+\mathrm{M} 2)\end{array}$} \\
\cline { 1 - 2 } $\begin{array}{c}\text { Mode 1 }(\mathrm{M} 1) \\
(3.6 \mathrm{~Hz})\end{array}$ & $\begin{array}{c}\text { Mode 2 (M2) } \\
(4.56 \mathrm{~Hz})\end{array}$ & $58.3 \mathrm{MPa}$ \\
\hline $\begin{array}{c}32.7 \mathrm{MPa} \\
\text { (Max. for M1) }\end{array}$ & $25.6 \mathrm{MPa}$ & $106.0 \mathrm{MPa}$ \\
\hline $6.0 \mathrm{MPa}$ & $\begin{array}{c}100 \mathrm{MPa} \\
\text { (Max. for M2) }\end{array}$ & 1006 \\
\hline
\end{tabular}

(a) Dynamic Stress for $\mathrm{DP}=100 \mathrm{kPa}$

\begin{tabular}{|c|c|c|}
\hline \multicolumn{2}{|c|}{ Stress Level } & \multirow[b]{2}{*}{$\begin{array}{c}\text { Total Stress } \\
(\mathrm{M} 1+\mathrm{M} 2)\end{array}$} \\
\hline $\begin{array}{l}\text { Mode } 1 \\
(3.6 \mathrm{~Hz})\end{array}$ & $\begin{array}{c}\text { Mode } 2 \\
(4.56 \mathrm{~Hz})\end{array}$ & \\
\hline $\begin{array}{c}28.9 \mathrm{MPa} \\
(\mathrm{Max} . \text { for } \mathrm{Ml})\end{array}$ & $1.5 \mathrm{MPa}$ & $30.4 \mathrm{MPa}$ \\
\hline $9.9 \mathrm{MPa}$ & $\begin{array}{c}88.2 \mathrm{MPa} \\
\text { (Max. for M2) }\end{array}$ & $98.1 \mathrm{MPa}$ \\
\hline
\end{tabular}

(c) Dynamic Stress for $\mathrm{DP}=500 \mathrm{kPa}$

\begin{tabular}{|c|c|c|}
\hline \multicolumn{2}{|c|}{ Stress Level } & \multirow{2}{*}{$\begin{array}{c}\text { Total Stress } \\
\text { (Mode 1+Mode } \\
\text { Mode } 1\end{array}$} \\
\hline $\begin{array}{c}\text { (3.6 Hz) } \\
\text { (M.2 MPa }\end{array}$ & $\begin{array}{c}\text { Mode } 2 \\
(4.56 \mathrm{~Hz})\end{array}$ & \begin{tabular}{c}
$65.7 \mathrm{MPa}$ \\
\hline $9.5 \mathrm{MPa}$
\end{tabular} \\
\hline $9.3 \mathrm{MPa}$ & $\begin{array}{c}78.5 \mathrm{MPa} \\
\text { (Max. for M2) }\end{array}$ & $87.8 \mathrm{MPa}$ \\
\hline
\end{tabular}

(e) Dynamic Stress for DP=700kPa

\begin{tabular}{|c|c|c|}
\hline \multicolumn{2}{|c|}{ Stress Level } & \multirow[b]{2}{*}{$\begin{array}{c}\text { Total Stress } \\
(\mathrm{M} 1+\mathrm{M} 2)\end{array}$} \\
\hline $\begin{array}{c}\text { Mode } 1(\mathrm{M} 1) \\
(3.6 \mathrm{~Hz})\end{array}$ & $\begin{array}{c}\text { Mode } 2(\mathrm{M} 2) \\
(4.56 \mathrm{~Hz})\end{array}$ & \\
\hline $\begin{array}{c}47.5 \mathrm{MPa} \\
(\mathrm{Max} \text { for } \mathrm{Ml})\end{array}$ & $21.3 \mathrm{MPa}$ & $68.8 \mathrm{MPa}$ \\
\hline $11.8 \mathrm{MPa}$ & $\begin{array}{c}91.1 \mathrm{MPa} \\
\text { (Max. for M2) }\end{array}$ & $102.9 \mathrm{MPa}$ \\
\hline
\end{tabular}

(b) Dynamic Stress for DP=200kPa

\begin{tabular}{|c|c|c|}
\hline \multicolumn{2}{|c|}{ Stress Level } & \multirow{2}{*}{$\begin{array}{c}\text { Total Stress } \\
(\mathrm{M} 1+\mathrm{M} 2)\end{array}$} \\
\hline $\begin{array}{c}\text { Mode } 1 \\
(3.6 \mathrm{~Hz})\end{array}$ & $\begin{array}{c}\text { Mode } 2 \\
(4.56 \mathrm{~Hz})\end{array}$ & $66.3 \mathrm{MPa}$ \\
\hline $\begin{array}{c}45.9 \mathrm{MPa} \\
\text { (Max. for M1) }\end{array}$ & $20.4 \mathrm{MPa}$ & $62.2 \mathrm{MPa}$ \\
\hline $24.9 \mathrm{MPa}$ & $\begin{array}{c}67.3 \mathrm{MPa} \\
\text { (Max. for M2) }\end{array}$ & 92.06 \\
\hline
\end{tabular}

(d) Dynamic Stress for DP $=650 \mathrm{kPa}$

\begin{tabular}{|c|c|c|}
\hline \multicolumn{2}{|c|}{ Stress Level } & \multirow[b]{2}{*}{$\begin{array}{c}\text { Total Stress } \\
(\mathrm{M} 1+\mathrm{M} 2)\end{array}$} \\
\hline $\begin{array}{l}\text { Mode 1 } \\
(3.6 \mathrm{~Hz})\end{array}$ & $\begin{array}{c}\text { Mode } 2 \\
(4.56 \mathrm{~Hz})\end{array}$ & \\
\hline $\begin{array}{c}45.4 \mathrm{MPa} \\
(\mathrm{Max} \text { for } \mathrm{Ml})\end{array}$ & $8.0 \mathrm{MPa}$ & $53.4 \mathrm{MPa}$ \\
\hline $12.0 \mathrm{MPa}$ & $\begin{array}{c}69.3 \mathrm{MPa} \\
\text { (Max. for M2) }\end{array}$ & $81.3 \mathrm{MPa}$ \\
\hline
\end{tabular}

(f) Dynamic Stress for $\mathrm{DP}=850 \mathrm{kPa}$

\begin{tabular}{|c|c|c|}
\hline \multicolumn{2}{|c|}{ Stress Level } & \multirow[b]{2}{*}{$\begin{array}{c}\text { Total Stress } \\
(\mathrm{M} 1+\mathrm{M} 2)\end{array}$} \\
\hline $\begin{array}{l}\text { Mode } 1 \\
(3.6 \mathrm{~Hz})\end{array}$ & $\begin{array}{c}\text { Mode } 2 \\
(4.56 \mathrm{~Hz})\end{array}$ & \\
\hline $\begin{array}{c}21.2 \mathrm{MPa} \\
(\mathrm{Max} . \text { for } \mathrm{Ml})\end{array}$ & $2.2 \mathrm{MPa}$ & $23.4 \mathrm{MPa}$ \\
\hline $8.2 \mathrm{MPa}$ & $\begin{array}{c}64.4 \mathrm{MPa} \\
\text { (Max. for M2) }\end{array}$ & $72.6 \mathrm{MPa}$ \\
\hline
\end{tabular}

(g) Dynamic Stress for DP $=950 \mathrm{kPa}$ 
Table 1 shows the high stress location for each vibration mode. The summation of the stresses for Mode 1 and Mode 2 at the same location will give the total stress values. The animated model in Figure 6 clearly showed that the dynamic stress during the operation is dominated for the main pipe by the by the $1^{\text {st }}$ mode at $3.6 \mathrm{~Hz}$, and for the secondary pipe by the $2^{\text {nd }}$ mode at $4.56 \mathrm{~Hz}$.

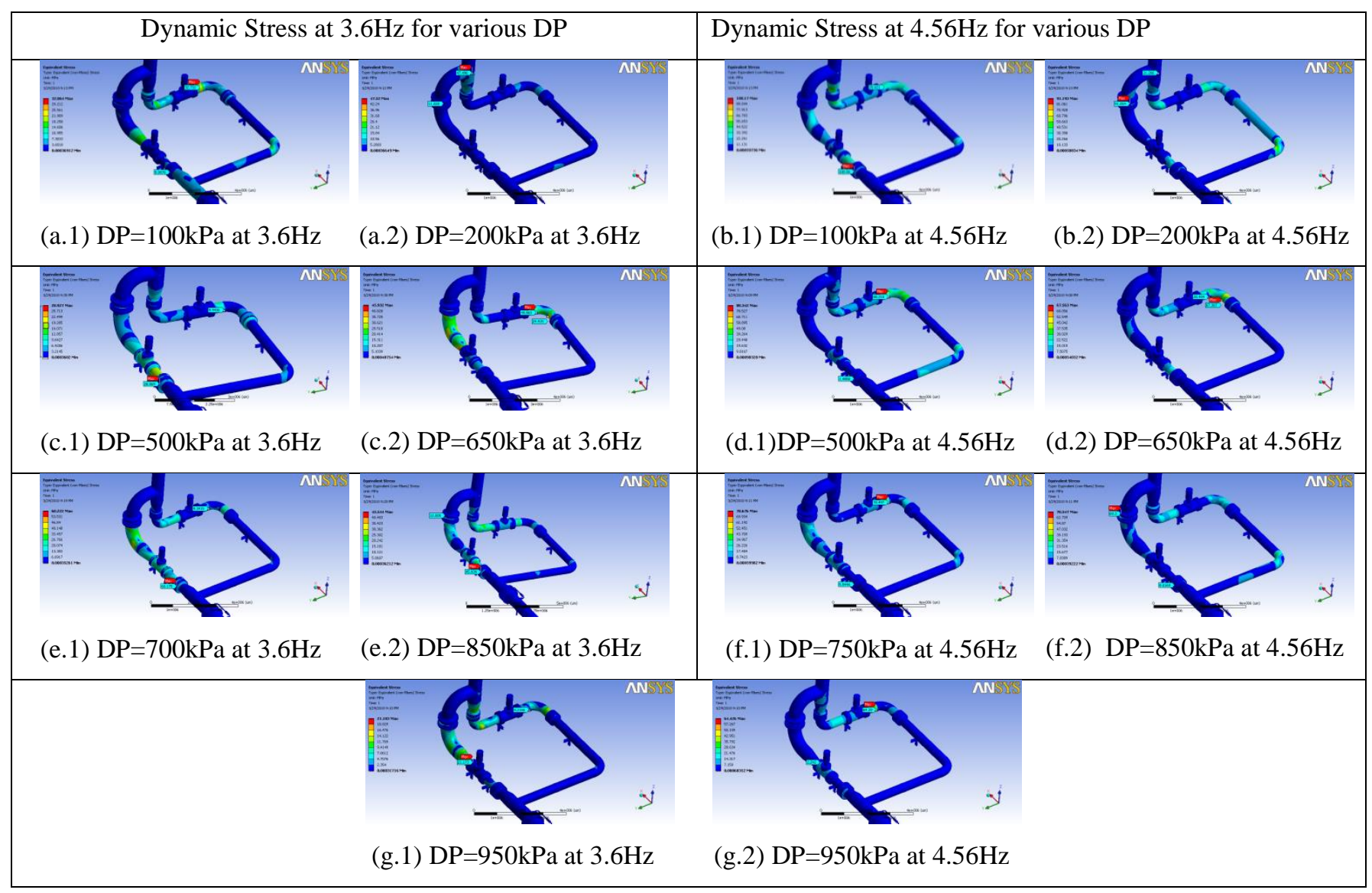

Figure 6. Dynamic Stress on the Pipe System at (left) $3.6 \mathrm{~Hz}$, and (right) $4.56 \mathrm{~Hz}$

Since it was observed that the flow generates random excitations, the case was treated as stiffness controlled situation. It was observed the lowest allowable endurance limit for dynamic stress intensity is equal to 13,600psi (93.8MPa) for indefinite lifecycle. Based on one location where the operating condition have been tested, the total stress level of DSS pipe are 41.42MPa and 51.82MPa which indicates that the stress level of the pipe is still under allowable endurance limit. Based on a different 
location testing, the total stress level of DSS pipe is $67.80 \mathrm{MPa}$ and $87.4 \mathrm{MPa}$. Overall, total stress for these two locations is near to the pipe stress allowable limit for indefinite lifecycle [27-29]. At $87.4 \mathrm{MPa}$, the stress is more than $90 \%$ of the indefinite cyclic stress level, which means insufficient safety margin for any design or calculation uncertainty. Failure can potentially occur even at this condition. Any fitting along the main pipe, e.g. instruments lines takeoff, gauges, drain valves and other small connections to the main pipe may experience higher stress due to their design and must be properly supported. These components are more likely to fail prior the main pipe, thus are tell tale sign of impending problems which is what we have seen now. In summary, the maximum dynamic stress level for 400mmscfd (Million standard cubic feet per day ) pipe flow rate can be summarized as in Figure 7 below.

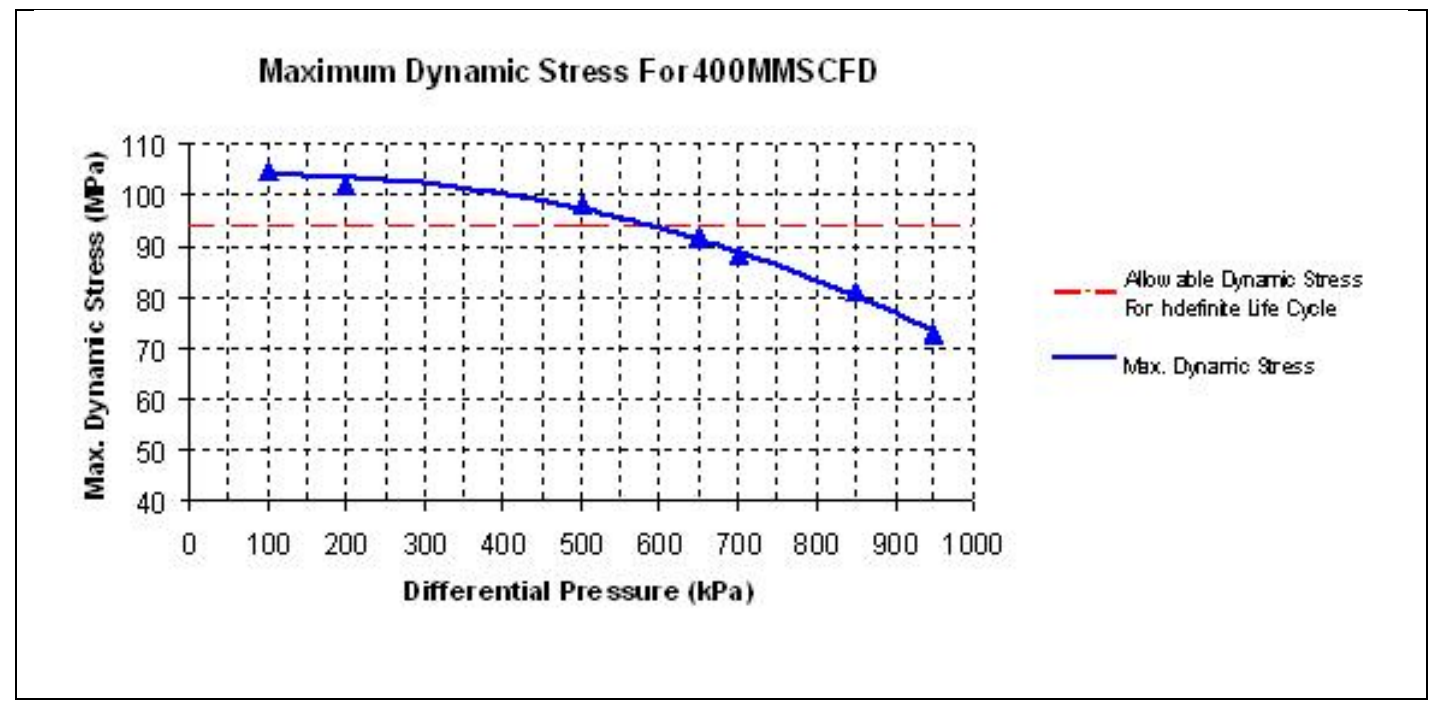

Figure 7. The Maximal Dynamic Stress for the Pipe Structure

\section{Conclusions}

In this paper, an investigation into the application of non-destructive evaluation techniques for in-service pipes has been presented. It was observed that the vibration level decreases corresponding to the increase of the Differential Pressure (DP) for the same flow rate. From Figure 3, the operation conditions for DP of $100 \mathrm{kPA}$ and $200 \mathrm{kPa}$ 
exceed the marginal line, while others are below marginal line. If vibration assessment are made purely base on vibration level from Figure 3, all operation conditions are not likely to fail. However, with proposed method of non-destructive testing and evaluation of these pipes, while in service, it is assessed that operation conditions for DP of $100 \mathrm{kPa}, 200 \mathrm{kPa}$ and $500 \mathrm{kPa}$ are mostly likely to encounter fatigue failure due to excess vibration as a result of cyclic force induced by the flow. The possible locations of fatigue failure are pinpointed in Figure 6. The analysis revealed that the pipe should maintain the differential pressure above a threshold level to ensure the pipe operates under the allowable dynamic stress for a "theoretically indefinite" life cycle. In future, fully coupled of fluid-structure interaction (FSI) analysis could be proposed where the site measurements work can be greatly reduced. Only single set of measurement is required for verification process of FE model. FSI analysis could then compute and predict the displacement of the pipe computationally which will be used as the input parameter in dynamic stress analysis. The drawback of this technique is the high computation time and cost needed in FSI analysis due to complex and fully coupled structure is being analyzed.

\section{References}

[1] R.D. Blevins, Flow-induced vibration, 2nd ed., Van Nostrand Reinhold, New York, 1990.

[2] S.-s. Chen, Flow-induced vibration of circular cylindrical structures, Hemisphere Pub. Corp., Washington, 1987.

[3] H.L. Dai, L. Wang, Q. Qian, J. Gan, Vibration analysis of three-dimensional pipes conveying fluid with consideration of steady combined force by transfer matrix method, Appl Math Comput, 219 (2012) 2453-2464. 
[4] G.P. Zou, N. Cheraghi, F. Taheri, Fluid-induced vibration of composite natural gas pipelines, International Journal of Solids and Structures, 42 (2005) 1253-1268.

[5] G.H. Koo, Y.S. Park, Vibration analysis of a 3-dimensional piping system conveying fluid by wave approach, Int J Pres Ves Pip, 67 (1996) 249-256.

[6] N. Sukaih, A practical, systematic and structured approach to piping vibration assessment, Int J Pres Ves Pip, 79 (2002) 597-609.

[7] L.N. Panda, R.C. Kar, Nonlinear dynamics of a pipe conveying pulsating fluid with combination, principal parametric and internal resonances, J Sound Vib, 309 (2008) $375-406$.

[8] W. Lin, N. Qiao, Y.Y. Huang, Dynamical behaviors of a fluid-conveying curved pipe subjected to motion constraints and harmonic excitation, J Sound Vib, 306 (2007) 955-967.

[9] S. Enz, J.J. Thomsen, Predicting phase shift effects for vibrating fluid-conveying pipes due to Coriolis forces and fluid pulsation, J Sound Vib, 330 (2011) 5096-5113.

[10] J.J. Thomsen, J. Dahl, Analytical predictions for vibration phase shifts along fluidconveying pipes due to Coriolis forces and imperfections, J Sound Vib, 329 (2010) 3065-3081.

[11] W.H. Semke, G.D. Bibel, S. Jerath, S.B. Gurav, A.L. Webster, Efficient dynamic structural response modelling of bolted flange piping systems, Int J Pres Ves Pip, 83 (2006) 767-776.

[12] R.H. Plaut, Postbuckling and vibration of end-supported elastica pipes conveying fluid and columns under follower loads, J Sound Vib, 289 (2006) 264-277. 
[13] A.G.A. Rahman, S. Noroozi, M. Dupac, S.M.S.M. Al-Attas, J.E. Vinney, A hybrid approach for nondestructive assessment and design optimisation and testing of inservice machinery, Nondestruct Test Eva, 28 (2013) 44-57.

[14] C. Devriendt, G. Steenackers, G. De Sitter, P. Guillaume, From operating deflection shapes towards mode shapes using transmissibility measurements, Mech Syst Signal Pr, 24 (2010) 665-677.

[15] O. Dossing, C.H. Staker, Operational deflection shapes: background, measurement and applications, in: Proceedings of 5th International Modal Analysis Conference London, UK, 1987, pp. 1372-1378.

[16] W.D. Marscher, C.-W. Jen, Use of operating deflection and mode shapes for machinery diagnostics, in: Proceedings of 17th International Modal Analysis Conference, Hyatt Orlando Hotel, Kissimmee, Florida, USA, 1999, pp. 2065-2071.

[17] P.L. McHargue, M.H. Richardson, Operating detection shapes from time versus frequency domain measurements, in: Proceedings of the 11th International Modal Analysis Conference, Kissimmee, USA, 1993, pp. 581-587.

[18] R. Pascual, J.C. Golinval, M. Razeto, On-line damage assessment using operating detection shapes, in: Proceedings of 17th International Modal Analysis Conference, Hyatt Orlando Hotel, Kissimmee, Florida, USA, 1999, pp. 238-243.

[19] B.H. Tongue, Principles of vibration, 2nd ed., Oxford University Press, New York, 2002.

[20] D.J. Ewins, Modal testing : theory, practice, and application, 2nd ed., Research Studies Press, Baldock, Hertfordshire, England ; Philadelphia, PA, 2000. 
[21] P. Mohanty, D.J. Rixen, A modified Ibrahim time domain algorithm for operational modal analysis including harmonic excitation, J Sound Vib, 275 (2004) 375-390.

[22] L. Hermans, H. Van der Auweraer, Modal testing and analysis of structures under operational conditions: Industrial applications, Mech Syst Signal Pr, 13 (1999) 193-216.

[23] L.M. Zhang, R. Brincker, P. Andersen, Modal Indicators for Operational Modal Identification, in: Proceedings of the 19th International Modal Analysis Conference, Orlando, Florida, USA, 2001, pp. 746-752.

[24] A.G.A. Rahman, Z. Ismail, S. Noroozi, Z.C. Ong, Enhancement of Impactsynchronous Modal Analysis with number of averages, Journal of Vibration and Control, 20 (2014) 1645-1655.

[25] A.G.A. Rahman, Z.C. Ong, Z. Ismail, Enhancement of coherence functions using time signals in Modal Analysis, Measurement, 44 (2011) 2112-2123.

[26] S.S. Rao, Mechanical vibrations, 5th ed., Prentice Hall, Upper Saddle River, N.J., 2011.

[27] J.C. Wachel, Piping Vibration and Stress, in: Vibration Institute, Machinery Vibration Monitoring and Analysis Seminar, New Orleans, LA, 1981, pp. 1-9.

[28] J.C. Wachel, S.J. Morton, K.E. Atkins, Piping Vibration Analysis, in: Proceedings of 19th Turbomachinery Symposium, Texas, USA, 1990, pp. 119-134.

[29] J.C. Wachel, Displacement Method For Determining Acceptable Piping Vibration Amplitudes, in: PVP-Vol. 313-2, International Pressure Vessels and Piping Codes and Standards: Volume 2, ASME 1995, pp. 197-208. 
